\title{
Gastric Inflammatory Fibroid Polyp Treated by Endoscopic Submucosal Dissection
}

\author{
Y. Hattori ${ }^{\mathrm{a}}$ S. Kobayashib ${ }^{\mathrm{b}} \quad$ H. Takahashi ${ }^{\mathrm{a}} \quad$ M. Yoneda

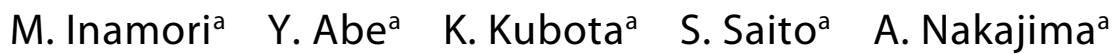 \\ ${ }^{a}$ Gastroenterology, Yokohama City University Graduate School of Medicine, \\ Yokohama, and ${ }^{\mathrm{b}}$ Gastroenterology, Chigasaki Municipal Hospital, Chigasaki, \\ Japan
}

\section{Key Words}

Inflammatory fibroid polyp · Endoscopic submucosal dissection

\begin{abstract}
The endoscopic examination of a 64-year-old male patient revealed a gastric submucosal tumor in the anterior wall of the gastric antrum. The lesion increased in diameter to $25 \mathrm{~mm}$ and was resected completely with endoscopic submucosal dissection (ESD). Histological examination of the submucosal tumor gave a diagnosis of an inflammatory fibroid polyp (IFP). It is suggested that ESD may be an effective and safe therapy for gastric submucosal tumors.
\end{abstract}

\section{Introduction}

Inflammatory fibroid polyps (IFPs) occur throughout the gastrointestinal tract but are usually seen in the colon, where they accompany a variety of inflammatory disorders, and are often difficult to diagnose by biopsy [1-4]. Gastric IFPs usually occur in the antrum or prepyloric region and may be a source of bleeding or outlet obstruction. We report a case of gastric IFP in which the lesion showed marked changes in morphological features and size within a short period of time; the diagnosis was made by endoscopic submucosal dissection (ESD).

\section{Case Report}

A 64-year-old man had been under regular endoscopic follow-up because of a gastric submucosal tumor in the anterior wall of the gastric antrum; examination of biopsy specimens had revealed normal mucosa. The lesion, which had been $15 \mathrm{~mm}$ in diameter in 2002, showed no change in size or shape at the first 4-year follow-up. However, in 2007, it was found to have developed two humps and to have 
increased in diameter to $25 \mathrm{~mm}$ ( $\underline{\text { fig. }}$ ). There were no specific physical findings, and hematological and biochemical examinations were within normal limits. Endoscopic ultrasonography showed a homogeneous hypoechoic lesion measuring $20 \mathrm{~mm}$ in diameter within the second layer of the gastric wall (fig. 2). ESD was performed with the patient's consent, and the diagnosis of IFP was made on histopathological examination of the resected specimen ( $\underline{\text { fig. } 3 \text { ). }}$.

\section{Discussion}

IFPs are rare benign lesions that may occur at any of various sites in the gastrointestinal tract, but are most commonly encountered in the distal stomach and distal ileum [5]. Endoscopic findings of IFPs are smooth sessile or pedunculated polyps. The final diagnosis of IFP depends on the pathological findings; however, the histological findings of the biopsy specimen are often difficult to diagnose $[4,6]$. In this case, it was covered almost completely by normal mucosa. It has been suggested that $H$. pylori may play a role in the pathophysiology of IFP, however, tests for H. pylori were negative in this case [7]. IFP was strongly suspected based on the findings on endoscopic ultrasonography in this case, and the lesion was resected by ESD. As gastric IFP is a benign tumor, it is seldom resected by endoscopic resection or surgery; however, IFPs are sometimes treated with endoscopic mucosal resection or ESD if the tumor is accompanied by malignant lesion or is increasing in size [8]. Endoscopic resection of IFP is unnecessary unless there is a rapid increase in size or association with neoplasm; however, careful observation is necessary in treating patients with gastric IFP. It is suggested that ESD may be an effective and safe therapy for gastric submucosal tumors.

Fig. 1. Endoscopic examination revealed two lump-shaped submucosal tumors of about $25 \mathrm{~mm}$ in diameter within a year.

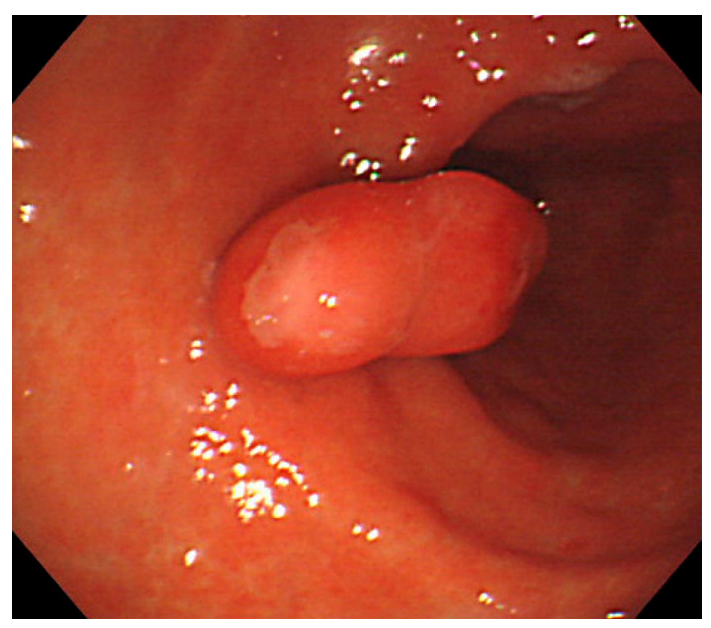




\begin{tabular}{r|l|l|l}
$\begin{array}{r}\text { Case Reports in } \\
\text { Gastroenterology }\end{array}$ & $\begin{array}{l}\text { Case Rep Gastroenterol 2008;2:283-286 } \\
\text { D0I: 10.1159/000151330 }\end{array}$ & Published online: August 19, 2008 & $\begin{array}{l}\text { @ 2008 S. Karger AG, Basel } \\
\text { ISSN 1662-0631 } \\
\text { www.karger.com/crg }\end{array}$ \\
\hline
\end{tabular}

Fig. 2. Endoscopic ultrasonography revealed a homogeneous hypoechoic lesion of $20 \mathrm{~mm}$ in diameter within the second layer.

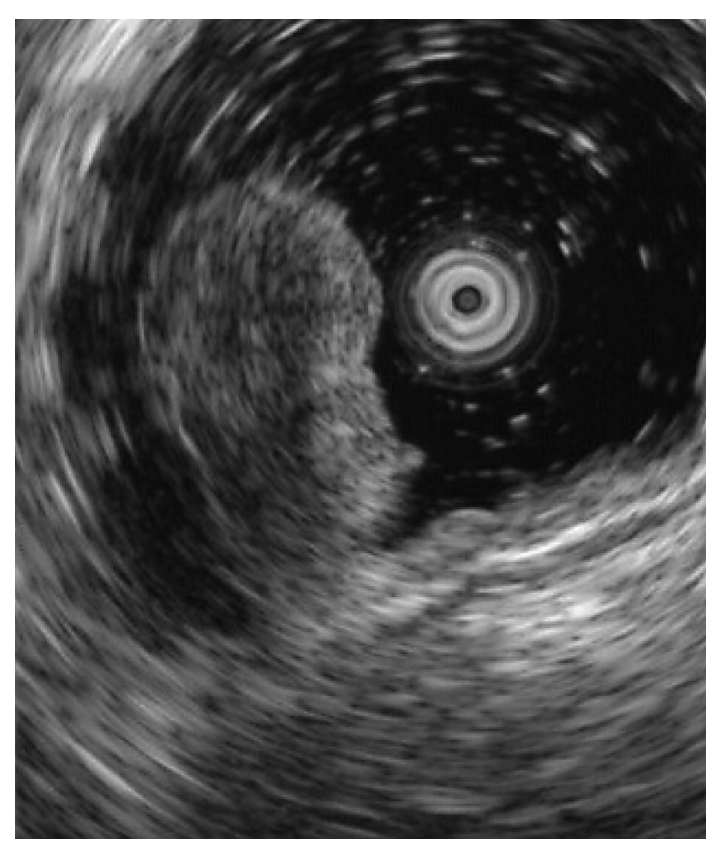

Fig. 3. IFP was diagnosed by histological examination. There was inflammatory infiltrate with eosinophils in the submucosa.

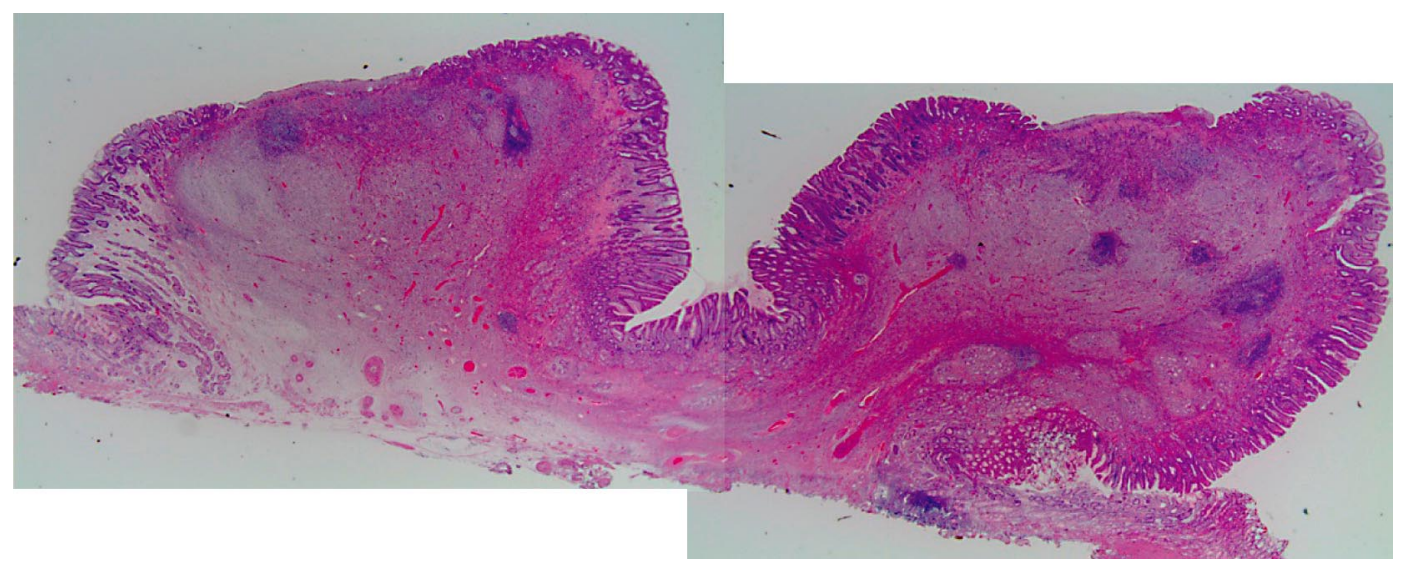




\section{References}

1 Hizawa K, Iida M, Tada S, Fuchigami T, Kuwano Y, Yao T, Fujishima M: Endoscopic evaluation of gastric inflammatory fibroid polyp. Surg Endosc 1995;9:397-400.

-2 Mori M, Tamura S, Enjoji M, Sugimachi K: Concomitant presence of inflammatory fibroid polyp and carcinoma or adenoma in the stomach. Arch Pathol Lab Med 1988;112:829-832.

-3 Mori M, Kakeji Y, Adachi Y, Korenaga D, Sugimachi K: Nonpolypoid inflammatory fibroid polyps concomitant with early carcinoma in the stomach. Eur J Surg Oncol 1992;18:632-635.

4 Hirasaki S, Endo H, Nishina T, Masumoto T, Tanimizu M, Hyodo I: Gastric cancer concomitant with inflammatory fibroid polyp treated with endoscopic mucosal resection using an insulation-tip diathermic knife. Intern Med 2003;42:259-262.

5 Kolodziejczyk P, Yao T, Tsuneyoshi M: Inflammatory fibroid polyp of the stomach. A special reference to an immunohistochemical profile of 42 cases. Am J Surg Pathol 1993;17:1159-1168.

-6 Hirasaki S, Tanimizu M, Tsubouchi E, Nasu J, Masumoto T: Gastritis cystica polyposa concomitant with gastric inflammatory fibroid polyp occurring in an unoperated stomach. Intern Med 2005;44:46-49.

-7 Nishiyama Y, Koyama S, Andoh A, Kishi Y, Yoshikawa K, Ishizuka I, Yokono T, Fujiyama Y: Gastric inflammatory fibroid polyp treated with Helicobacter pylori eradication therapy. Intern Med 2003;42:263-267.

8 Nishio A, Ueda S, Ohkuma M, et al: A case of inflammatory fibroid polyp of the stomach which increased for a short period after cauterizing the superficial mucosa (in Japanese, with English abstract). Gastroenterol Endosc 1992;34:13241331. 